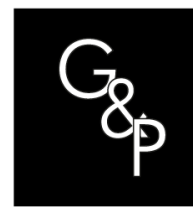

\title{
A bibliometric-qualitative study about the use of System Dynamics in the areas of Project and Program Management
}

\author{
Um estudo bibliométrico e qualitativo sobre o uso da dinâmica de \\ sistemas nas áreas de gerenciamento de projetos e programas \\ Luciano da Silva Bastos Sales ${ }^{1}$ (i), Sanderson Barbalho² (i), Rodrigo Augusto ${ }^{3}$ \\ ${ }^{1}$ Exército Brasileiro, Departamento de Ciência e Tecnologia, Brasília, DF, Brasil. E-mail: lucianofrc@gmail.com \\ ${ }^{2}$ Universidade de Brasília - UnB, Departamento de Engenharia de Produção, Brasília, DF, Brasil. E-mail: \\ sandersoncesar@unb.br. \\ ${ }^{3}$ The University of Texas at Arlington, Computer Science Department, Arlington, Texas, USA. E-mail: \\ rasandequis@gmail.com
}

How to cite: Sales, L., Barbalho, S. and Augusto, R. (2021). A bibliometric-qualitative study about the use of System Dynamics in the areas of Project and Program Management. Gestão\&Produção, 28(4), e5770. https://doi.org/10.1590/1806-9649-2021v28e5770

\begin{abstract}
Despite the proliferation as well as great advances in the development of dynamic models applied to project management, research that applies system dynamics principles to program management does not seem to be as fertile. The objective of this paper is to obtain a more accurate vision of how the system dynamics theory is being used in the development of the program management field. The bibliometric-qualitative study confirms there is a robust use of system dynamics tools in the project management area, with a wide range of applications as well as solid results. The study, however, also shows that for programs, despite a noticeable increase regarding the interest in program management by organizations, clearly there is much less research uniting program management and system dynamics. More importantly, some dynamic models are being used to improve the performance of programs, however, few studies take into consideration the specific variables from program management. Thus, we conclude that current research on these two topics can only be viewed as fragmented and in its early stages, offering ample room for improvement.
\end{abstract}

Keywords: System dynamics; Project management; Program management; Programme management.

Resumo: Apesar da proliferação e dos grandes avanços no desenvolvimento de modelos dinâmicos aplicados ao gerenciamento de projetos, a pesquisa acerca dos princípios da dinâmica do sistema aplicados ao gerenciamento de programas não é tão comum. O objetivo deste artigo é obter uma visão mais precisa sobre como a dinâmica do sistema está sendo usada no desenvolvimento do campo de gerenciamento de programas. $O$ estudo bibliométrico-qualitativo confirma que existe um uso robusto de ferramentas de dinâmica de sistemas na área de gerenciamento de projetos, com uma ampla gama de aplicações e resultados sólidos. O estudo, no entanto, também mostra que, para os programas, apesar do aumento notável quanto ao interesse das organizações pelo gerenciamento de programas, claramente há muito menos pesquisas unindo o gerenciamento de programas e a dinâmica do sistema. Mais importante, existem alguns modelos dinâmicos sendo usados para melhorar o desempenho dos programas, no entanto, poucos estudos levam em consideração as variáveis específicas do gerenciamento de programas para a sua construção. Assim, concluímos que as pesquisas atuais sobre

Recebido em: 10/Jan/2020 - Aceito em: 19/July/2020

Financial support: None. 
esses dois campos de pesquisa só podem ser vistas como fragmentadas e em seus estágios iniciais, o que oferece amplo espaço para melhorias.

Palavras-chave: Dinâmica de sistemas; Gerenciamento de projetos; Gerenciamento de programas.

\section{Introduction}

System dynamics (SD) is an effective method for modeling and analyzing complex variables, dynamic and non-linear interaction (Zhang et al., 2014). SD aims to understand how the main components within a specific system interact among themselves, making it easy to understand the relation between the system behavior across time, its underlying structure, and its decision rules, being applied to a wide array of disciplines (Yuan et al., 2012). SD clarifies deep, but often isolated and fragmented, knowledge, improving management understanding by explicitly representing complex interactions among many variables in nonlinear feedback loops (Trammell et al., 2016).

According to Lyneis \& Ford (2007), the project management field is one of the most successful in applying SD, since a series of models were developed to leverage this area's development, with wide applications and consistent results. From Dynamic Project Management (DPM) researches it is possible to find fundamental problems in the project management traditional approaches, to justify the inclusion of the dynamic paradigm to leverage the project results.

One of the issues cited by several researchers is the " $90 \%$ syndrome". Ford \& Sterman (2003) discuss the mentioned syndrome. According to this theory, the projects flow normally until they reach, approximately, $90 \%$ of their schedule, when they start to present delays and become, without any explanation, slower and slower. These authors show how common processes that occur in projects, such as the overlap of tasks and delays in the discovery of rework, can create non-planned iterations, generating delays, higher costs, and inferior quality. In other words, these iterations, through time, make the project work to generate more rework, which constitutes the cause of the mentioned syndrome.

Another issue, explained by Williams (2005) is the reductionist view of management through the decomposition of elements of a project. In the traditional approaches, a project is represented through the sum of its work packages, after all the fundamental assumption behind these approaches is that the more detailed the planning, the higher the chances of project success. In the case of the dynamic approach, a project is seen as a continuous flow of work packages, with several variables, not always intuitive, influencing the project result. Therefore, previously scientific research mapped problems that occur specifically in the project management area, which can be well understood by the use of system dynamic tools.

Recently, the works of Barbalho et al. (2019a) and Barbalho et al. (2019b) open new possibilities of research in new product development projects utilizing mathematical modeling of the timeframe for these projects through system dynamics theory. These models demonstrate that product complexity and team seniority can predict project time performance with less than a $15 \%$ error rate. Despite been more used as a post-morten analysis (Sterman, 2000) in the project management field in the past, this example of a new way of applying system dynamics on new product projects shows the power of this theory for helping companies to improve their project planning and success.

Organizations of the knowledge economy are characterized by changes, and programs are a means to make major changes and transformations in organizations and businesses (Martinsuo \& Hoverfält, 2018). This is one of the reasons why organizations are becoming increasingly aware and interested in the discipline of program management (Shehu \& Akintoye, 2010). According to Martinsuo \& Lehtonen (2007), programs can be defined as 
sets of projects and actions purposely grouped to complete a process of transformation and thus to obtain strategic benefits. This way, it is a combination of all projects needed within a program, that will result in benefits that will create value for the organizations.

According to Sales \& Barbalho (2018), like project management, program management requires the use of the system dynamics tools to leverage its benefits delivery, avoiding the occurrence of system archetypes, with the capacity to destroy the program's ability to generate benefits. In research developed by Conforto et al. (2013), Program Managers and Chief System Engineer, indicated "system thinking" as the principal critical skill to program management. "SD" is one of the tools to make systemic thinking viable. SD models are powerful tools to help one to understand and to leverage the feedback interrelationships of complex management systems (Cosenz, 2017), such as, for example, the structure of program management.

Taking into consideration what was presented so far, it seems important for organizations to know the dynamic models used in program management to improve their decision making. This study will perform a bibliometric-qualitative study analysis of the scientific literature about the use of SD and its applications to project and program management. This study will seek to identify the main authors, publications, trends, and approaches used in the most relevant papers of each field (projects and programs).

The objective of this paper is to obtain a more accurate vision of how SD has been used in the development of the program management field, the influence exercised by DPM over program management, and the identification of new research paths, absent from the current literature, and that thus represent research gaps. To reach this objective, this research will try to answer the following Research Questions (RQ):

RQ1. What is the current state of the researches related to the use of SD in the fields of project and program management?

$R Q 2$. Which is the level of influence of the researches related to the use of SD in the project management to the development of field research in program management?

$\mathrm{RQ3}$. Which are the trends for the development of SD for the program management field?

To reach this objective, it will be presented in section 2, the methodology being used; in section 3, the results and discussions; and finally, in section 4, the conclusions of this work.

\section{Methodology}

The systematic literature review allows researchers to collect, analyze, and integrate academic contributions under a determined research theme in a repeatable and transparent fashion (Danwitz, 2017). As the quality of the bibliometric analysis depends on the selected set of data (Rezende et al., 2018), the procedures adopted in this research used mixed approaches, applying qualitative and quantitative methods to make it possible to integrate and analyze the literature, thus minimizing interpretation problems, as suggested by Oraee et al. (2017). According to these researchers, the intention of adding a qualitative step to the systematic analysis process is to allow the synthesis where the authors do not create a new theory, but identify what the different studies tell, as well as their respective gaps.

The framework SALSA (Search, AppraisaL, Synthesise Analysis), proposed by Booth et al. (2013) was used in this research. Figure 1 illustrated the protocol being followed for this mixed method of the systematic review. The details about the stages, as illustrated in Figure 1, are discussed next. 


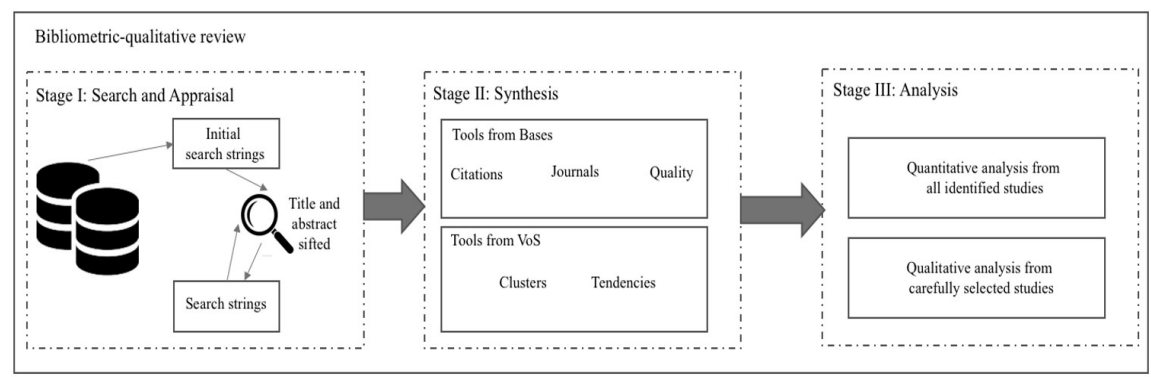

Figure 1. Research protocol.

\section{Stage I: Definition of search procedures and initial evaluation (Search and Appraisal)}

The realization of a theoretical review about the use of SD on the fields of project and program management starts with the choice of databases that will compose the sample base. The databases used in this research were both Web of Science (WoS) and Scopus, and the search procedures happened in March 2019.

Once defined the scientific databases to be used, the choice of keywords or search strings was started. The first strategy was an "inclusive strategy", where we tried to concatenate in a single string as many terms as possible, such as "system dynamics" to the terms "project" and "project management" (with a focus in SD application to the project field), "system dynamics" to the terms "program", "programme", "program management" and "programme management" (with focus on SD application to the program field). These terms were employed in the search fields of "keyword", "title" and "abstracts" of published papers, from XXI century forward, in order words, papers, and conference papers published between 2001 and 2018.

This strategy proved to be non-optimal, as, after a non-structured reading of titles and abstracts of the most cited papers, it was realized that a large number of returned papers could not be used by this research, as they were overwhelmingly non-related to its "management" key aspect. After careful reconsideration, it was decided to adopt a fractioned search approach, based on multiple specialized search strings instead of a single generic one. The returned results, after new non-structured reading of titles and abstracts of the most cited papers, proved to be more adequate in terms of its management association, however, the number of returned papers significantly decreased, thus leading to the decision of once again to be as inclusive as possible from this point forward, through the inclusion of all returned papers into the research, without the adoption of a previous title and/or abstract intermediary screening/elimination process.

This way, to start the scrutiny of the papers from a more representative sample, it was defined to come up with a joint group of the six research forms to compose the initial mass of papers for the start of selection and analysis activities, as it can be observed in Chart 1 (Scopus) and Chart 2 (WoS).

Chart 1. Search strings applied to Scopus database.

\begin{tabular}{|l|}
\hline P1: ((TITLE-ABS-KEY ("project management") AND TITLE-ABS-KEY("system dynamics")) AND \\
DOCTYPE (ar OR cp) AND PUBYEAR > 2000 AND PUBYEAR < 2019). \\
\hline P2: ((TITLE-ABS-KEY ("program management") AND TITLE-ABS-KEY("system dynamics")) AND \\
DOCTYPE (ar OR cp) AND PUBYEAR > 2000 AND PUBYEAR < 2019). \\
\hline P3: ((TITLE-ABS-KEY ("programme management") AND TITLE-ABS-KEY("system dynamics")) \\
AND DOCTYPE (ar OR cp) AND PUBYEAR > 2000 AND PUBYEAR < 2019).
\end{tabular}


Chart 2. Search strings applied to WoS database.

\begin{tabular}{l} 
P4: Tópico: ("project management") AND Tópico: ("system dynamics") Refinado por: Tipos de \\
documento: (ARTICLE OR PROCEEDINGS PAPER) Tempo estipulado: 2001-2018.). \\
\hline P5: Tópico: ("program management") AND Tópico: ("system dynamics") Refinado por: Tipos de \\
documento: (ARTICLE OR PROCEEDINGS PAPER) Tempo estipulado: 2001-2018.). \\
\hline $\begin{array}{l}\text { P6: Tópico: ("programme management") AND Tópico: ("system dynamics") Refinado por: Tipos } \\
\text { de documento: (ARTICLE OR PROCEEDINGS PAPER) Tempo estipulado: 2001-2018.). }\end{array}$
\end{tabular}

To facilitate the understanding, the researched areas will be called Themes, being named as shown in Chart 3, below:

Chart 3. Research themes.

\begin{tabular}{|c|c|}
\hline Researched area & Paper denomination \\
\hline Use of SD in project management & Theme 1 \\
\hline Use of SD in program management & Theme 2 \\
\hline
\end{tabular}

The searches, as defined in Chart 1 and 2, returned a total of 7 papers (Scopus) and 3 papers (WoS) for Theme 2, and 295 papers (Scopus) and 125 papers (WoS) for Theme 1. For Theme 2, were obtained 7 unique records.

It is important to note that the period of analysis (2000 - 2018) was chosen because the main articles on the theme of project management and systems dynamics, before the 21st century are synthesized in Lyneis \& Ford (2007), in one of the most cited works for this area of research. Besides, there was no record of articles addressing programs and systems dynamics before the analyzed period.

\section{Stage II: Synthesis of the papers}

The second stage was put into practice to identify standards, leading to the development of an academic outline. Besides the information extracted from the databases, it was attempted, with the intent to measure the quality of the publications, the impact factor of the identified periodicals (CiteScore). The Software VOSViewer, developed by Van Eck \& Waltman (2010) was also used, with the intent to build and represent bibliometric maps, as well as identify clusters and trends.

\section{Stage III: Paper analysis}

The analysis of the selected paper portfolio for the development of the bibliometric analysis was divided into two steps: quantitative and qualitative respectively. In the quantitative step, all papers obtained for the two themes were analyzed, with the focus being on answering research questions "RQ1" and "RQ2".

As such, in the qualitative step, all papers related to theme 2 were used, with the focus being on the research question "RQ3". So, the papers of Theme 2 were analyzed more profoundly, with the intent to understand the dynamic application in each area. All proceedings were carried out by two researchers, independently, seeking to provide more safety to all obtained and analyzed data. The paper "A Dynamical Model of Program Management Construction Projects", from Theme 2, was not analyzed because it was not of open source and could not be found through the use of other techniques. 


\section{Results and discussion}

The results of this study will be presented in three sections. Section 3.1 will be dedicated to quantitative analysis, section 3.2 will be dedicated to qualitative analysis and section 3.3 will be dedicated to the discussions about the found results.

\subsection{Quantitative analysis}

The quantitative analysis has as objective to explore aspects related to the publications about the two research themes and will be presented in two sub-items: the relevance of researches in the two themes, as well as the influence analysis of theme 1 over the theme 2.

\subsubsection{The relevance of the two themes}

The use of SD in the two themes was analyzed, first under the perspective of the number of publications, of the number of citations, and of the impact of the main journals that publish studies about these themes. Figures 2 and 3 show the evolution of publications and citations, in each of the themes, within the period 2001-2018, in the two researched databases.

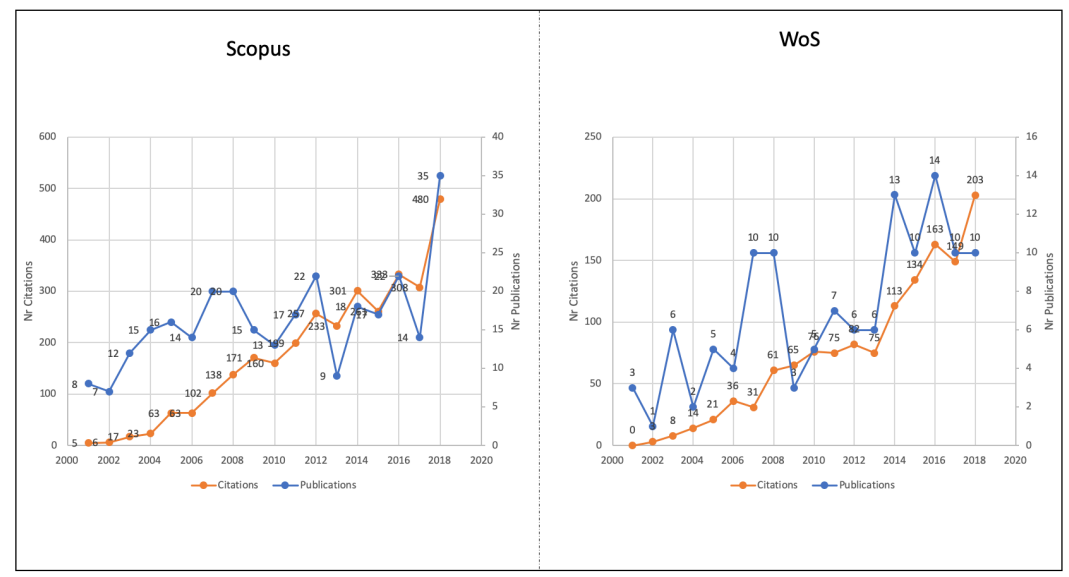

Figure 2. Evolution of publications and citations on Theme 1.

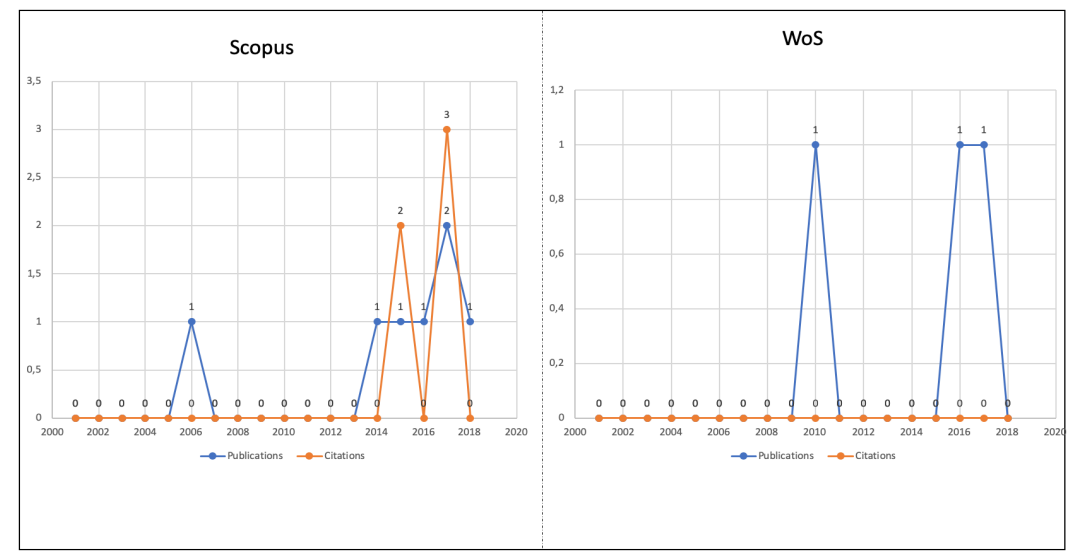

Figure 3. Evolution of publications and citations on Theme 2. 
In Figure 2, it becomes evident a consistent increase in the number of publications until 2018 , about Theme 1, with a perceptible decrease in 2017. However, similarly, there was a significant decrease in 2013 , on both databases, followed in the next years by a new increase. Still, in Figure 2, it is realized a consistent increase in the number of citations related to Theme 1, which denotes a progressive increase in the scientific interest about this theme.

It is realized, in Figure 3, that the number of publications about Theme 2 is still small, thus becoming evident a reduced number of researches carried out on top of these two knowledge fields. In Figure 3, it is perceived a small increase trend about Theme 2 (on both databases) in the last years, with at least one publication about such themes from 2014 forward. Still in Figure 3, one observes little scientific interest regarding Theme 2, to the point, there is not even one single citation about this theme at the WoS database.

Artto et al. (2009), in a bibliometric paper about program management, realized that one of the main gaps about programs and projects is that both the theoretical and practical bases in these two areas are largely ignored, and this could lead to programs being treated as large projects. It is possible that this confusion about the concepts makes SD models for projects to be used, inappropriately, in programs, or that the program theme to be handled within the papers of Theme 1, which would harm the specific research regarding Theme 2. This will be discussed in section 3.3 of this research.

According to Table 1, adding to the two bases, Theme 1 has the largest or a consolidated number of published papers in the magazines "International Journal of Project Management", "Journal of Construction Engineering and Management" and "System Dynamics Review”.

Table 1. Most prolific sources (Theme 1).

\begin{tabular}{lccc}
\hline \multicolumn{1}{c}{ Periodical title } & Publication \# & CiteScore 2018 & Base \\
\hline International Journal of Project Management & 13 & 6.41 & Scopus \\
\hline Journal of Construction Engineering and & 11 & 3.33 & Scopus \\
Management & 6 & 4.98 & Scopus \\
\hline European Journal of Operational Research & 5 & 1.27 & Scopus \\
\hline System Dynamic Review & 5 & 0.265 & Scopus \\
\hline Software Process Improvement and Practice & 6 & 1.27 & WoS \\
\hline System Dynamic Review & 4 & 2.24 & WoS \\
\hline IEEE Transactions on Engineering Management & 5 & 6.41 & WoS \\
\hline International Journal of Project Management & 4 & 1.48 & WoS \\
\hline Procedia Computer Science & 4 & 6.35 & WoS \\
\hline Automation in Construction & 4 & 2.51 & WoS \\
\hline Project Management Journal & & & \\
\hline
\end{tabular}

Taking into consideration the CiteScore, we can conclude that the main magazines with publications about Theme 1 are well-positioned, relevant, and having a high impact. In order words, Theme 1 seems to be mature enough to reach this kind of quality publication. The same degree of relevance cannot be attributed to the publications regarding Theme 2 (Table 2). Most of these publications were presented in conferences and even from those who have CiteScore, only three have an index greater than one, the researches published in 2016, 2017 and 2018, which can mean a trend, a better quality of research and at the same time an increase of scientific interest. 
Table 2. Most prolific sources (Theme 2).

\begin{tabular}{lccc}
\hline \multicolumn{1}{c}{ Periodical title } & Publication \# & CiteScore 2018 & Base \\
\hline $\begin{array}{l}\text { IEEE Transactions on Engineering } \\
\text { Management }\end{array}$ & 1 & 2.24 & Scopus \\
\hline $\begin{array}{l}\text { Journal of Defense Modeling and } \\
\text { Simulation }\end{array}$ & 1 & 0.81 & Scopus \\
\hline $\begin{array}{l}\text { Procedia Computer Science } \\
\text { Advances in Intelligent Systems and }\end{array}$ & 1 & 1.48 & Scopus \\
\hline $\begin{array}{l}\text { Womputing } \\
\text { Water Alternatives }\end{array}$ & 1 & 0.54 & Scopus \\
\hline $\begin{array}{l}\text { Data Processing and Quantitative } \\
\text { Economy Modeling }\end{array}$ & 1 & 2.70 & Scopus \\
$\begin{array}{l}\text { Proceedings of the International Design } \\
\text { Conference }\end{array}$ & 1 & - & WoS \\
$\begin{array}{l}\text { Proceedings of the Design 2016 14 } \\
\text { International Design Conference }\end{array}$ & 1 & - & WoS \\
\hline
\end{tabular}

Besides, we sought to understand the main institutions behind the analyzed papers, thus identifying the origins of the main researches on the theme of project management and systems dynamics (Figure 4 and 5). In both bases, Massachusetts Institute of Technology (MIT) was the main source of articles on this subject.

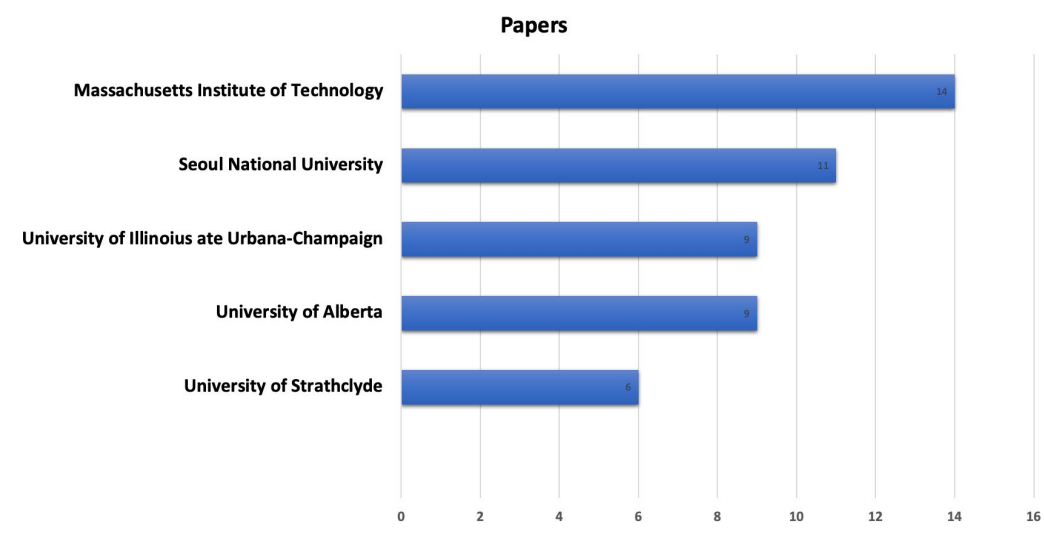

Figure 4. Origin of analyzed papers (Scopus).

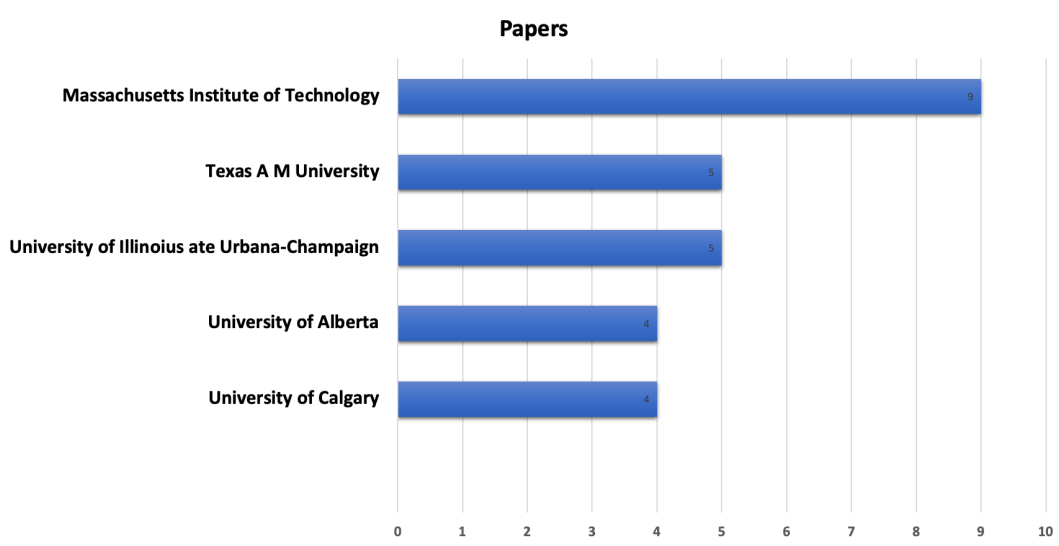

Figure 5. Origin of analyzed papers (WOS). 


\subsubsection{Clusters and trends}

To understand the influence of Theme 1 over Theme 2, three search strategies were adopted through VOS software: the analysis of the most cited authors, of the keywords, and the main terms underuse in the titles and the abstracts.

\subsubsection{Influence of Theme 1 over Theme 2 (cited authors)}

It was analyzed if the main authors being cited in the researches related to Theme 1 are the same being cited in Theme 2 , which could make it evident there is influence among the themes. To identify the authors who were most cited within the two Themes, following the recommendations of its developers, the VOS software was configured to perform "fractional counting".

Besides this, the minimum number of citations of an author to both bases was defined as 20 for Theme 1, a number that made possible the construction of a map with authors that formed clusters. Taking into consideration the small number of papers identified for Theme 2 , the minimum number of citations of a given author for the two bases was defined as 2 .

In the Scopus database, 49 authors reached the minimum number of citations. In the WOS database, 15 authors reached the established number of citations. These were the authors used to create the Theme 1 nets, presented in Figure 6 (A: Scopus and B: WOS).

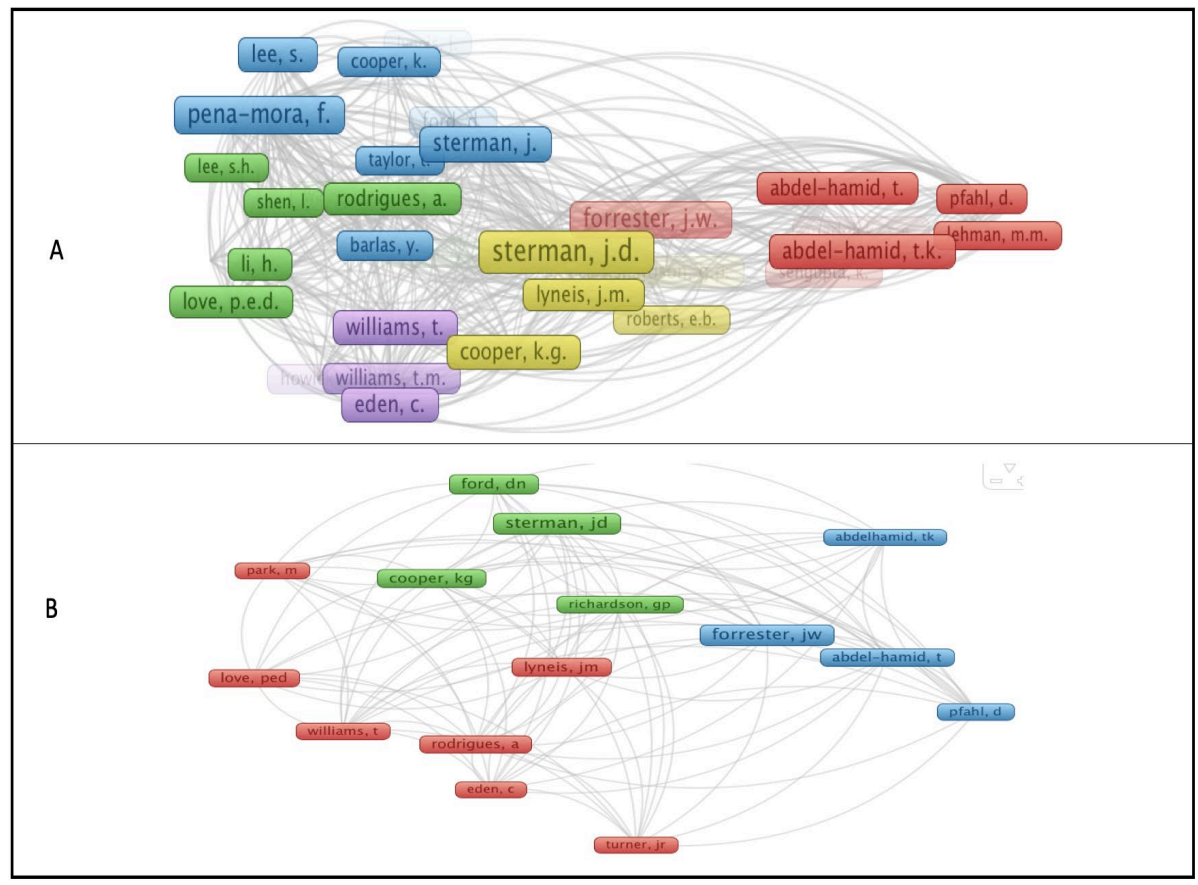

Figure 6. Clusters formed by the authors cited by Theme 1 papers.

Five clusters were formed (Figure 6), with highlights for the following authors: Sterman, Lyneis, Love, Williams, Ford, and Abdel-Hamid.

In Theme 2, the Scopus database, 23 authors reached the minimum number of citations. In the WOS database, 7 authors reached the established number of citations. These were the same authors used to create the nets represented in Figure 7(A: Scopus and B: WOS). 


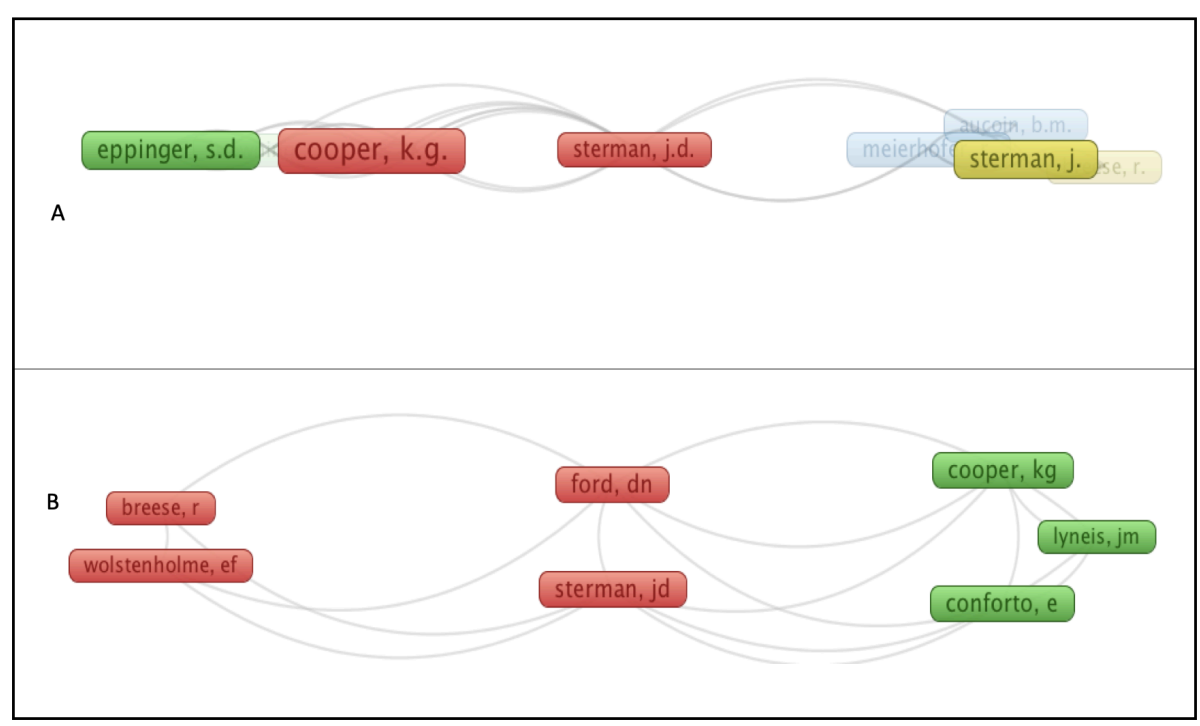

Figure 7. Clusters formed by the authors cited by Theme 2 papers.

Four clusters were formed (Figure 7), with highlights for the following authors: Sterman, Cooper, Breese, and Lyneis. Therefore, there is a convergence between the authors in both Themes. Chart 4 is presented all authors cited and that was used for the construction of the nets in Figure 6 and Figure 7. In blue are authors of Theme 1 and that are cited in researches related to Theme 2. In red, the cited authors in papers of Theme 2 and that are cited in Theme 1. We can thus notice that 33\% of authors cited in Theme 2 are shared with Theme 1, which seems to indicate an important influence, signaling that researches of Theme 2, although recent, share a mature knowledge database, since Theme 1 already presents robust and recognized results.

Chart 4. More cited authors from themes.

\begin{tabular}{|c|c|}
\hline More cited authors (Theme 2) & More cited authors (Theme 1) \\
\hline Cooper, K. & Sterman, J. \\
\hline Ford, D. & Forrester, J. \\
\hline Rebentisch, E. & Pena-Mora, F. \\
\hline Lyneis, J. & Park, M. \\
\hline Conforto, E. & Cooper, K. \\
\hline Sterman, J. & Ford, D. \\
\hline Oehmen, J. & Abdel-hamid, T. \\
\hline Rossi, M. & Williams, T. \\
\hline Eppinger, S. & Eden, C. \\
\hline Browning, T. & Lee, S. \\
\hline Marle, F. & Love, P. \\
\hline Vidal, L. & Rodrigues, A. \\
\hline Bocquet, J. & Madnick, S. \\
\hline Meierhofer, R. & Ackermann, F. \\
\hline Williams, T. & Lyneis, J. \\
\hline Clasen, T. & Li, h. \\
\hline Barlas, Y. & Bowers, J. \\
\hline Breese, R. & Pfahl, D. \\
\hline
\end{tabular}


Chart 4. Continued...

\begin{tabular}{|l|c|}
\hline More cited authors (Theme 2) & More cited authors (Theme 1) \\
\hline & Madachy, R. \\
\hline & Richardson, G. \\
\hline & Boehm, B. \\
\hline & Eppinger, S. \\
\hline & Han, S. \\
\hline & Senge, P. \\
\hline & Howick, S. \\
\hline & Lehman, M. \\
\hline & Ongulana, S. \\
\hline & Shen, L. \\
\hline & Barlas, Y. \\
\hline & Reppenning, N. \\
\hline & Ruhe, G. \\
\hline & Roberts, E. \\
\hline & Irani, Z. \\
\hline & \\
\hline & \\
\hline & \\
\hline & \\
\hline & \\
\hline & \\
\hline &
\end{tabular}

\subsubsection{Influence of Theme 1 over Theme 2 (keywords, title, and abstract)}

Seeking to provide a better comprehension of specific subjects presented in Theme 1, initially, a net based on the keywords used by the authors was presented. This way it was possible to verify if any sort of integration with the Theme 2 occurs within the dynamic project researches.

Following the recommendations of the system developers, VOS was set up to perform "fractional counting" over the keywords. Besides this, the minimum number of occurrences to both bases was defined as 2 . In the Scopus database, 110 words reached a minimum number of occurrences. In the WOS database, 55 words reached the minimum number of occurrences. These were the keywords used to create the nets of Theme 1, presented in Figure 8 (A, Scopus, and $\mathrm{B}, \mathrm{WoS}$ ). The different colors represent the evolution in the use of keywords over time, as represented by the used and available legend in the Figure itself.

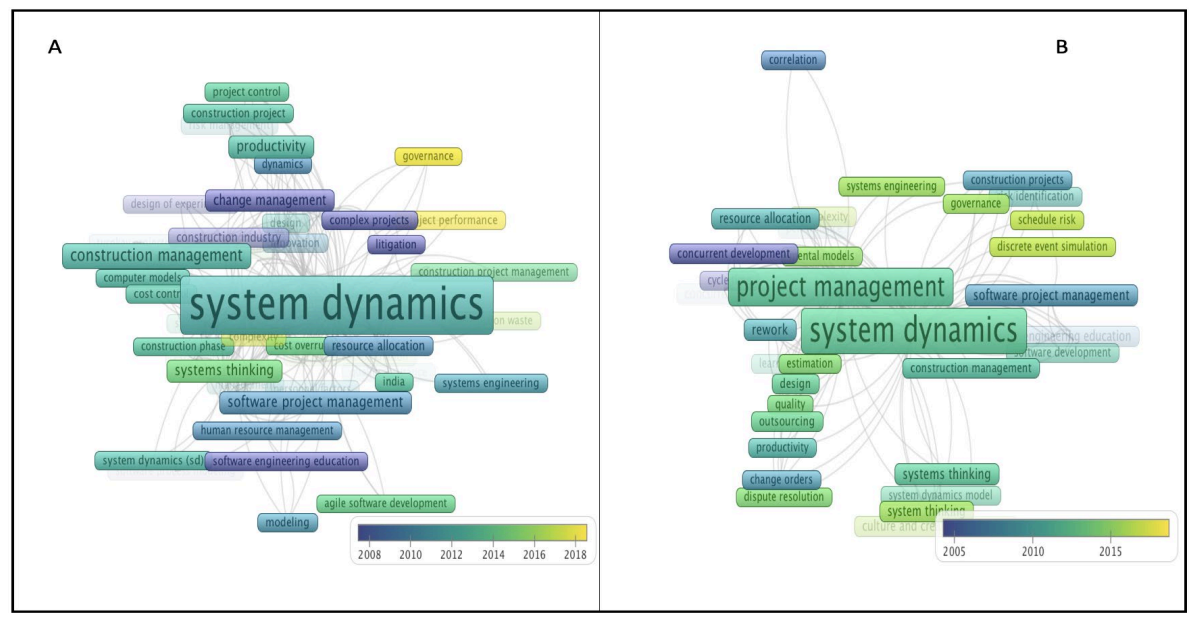

Figure 8. Net formed by keywords used by Theme 1 papers. 
According to Reis et al. (2017), the analysis of keywords can indicate the trajectory of research in a predetermined area. Through the analysis of keywords used in Theme 1, we tried to check if the keywords "Programs" or "Programme" were used throughout the analyzed period. This way, it would be possible to understand if, from the maturation of the researches with dynamic projects, the complementary and correlated theme would be explored.

Of the 165 words, considering the two bases, there is not even one single mention to the words "Programs" or "Programme", which seems to indicate that Theme 1 follows its trajectory, focused on problems of project management and dynamic systems, these last two being the keywords more used in both bases. However, it is important to note that the keyword "governance" is observed in more recent research, which will be discussed later.

Additionally, using VOSviewer's capability for text mining, it was verified the utilization of the words "Programs" and "Programme" in the titles and abstracts of papers of Theme 1. The software was set up, so it could create a co-occurrence net, following the same guidance obtained from the software developers, the "binary counting". Besides that, the minimum number of occurrences for both bases was defined as 2 .

In the Scopus database, 1176 words reached the minimum number and 529 words in the WOS database did the same. With VOSviewer set to its standard configurations, $60 \%$ of the terms with greater relevance are used to create the net. This way, 706 words were used from the Scopus database and 317 words were used from the WoS database, according to Figure 9 (A, Scopus, and B, WoS).

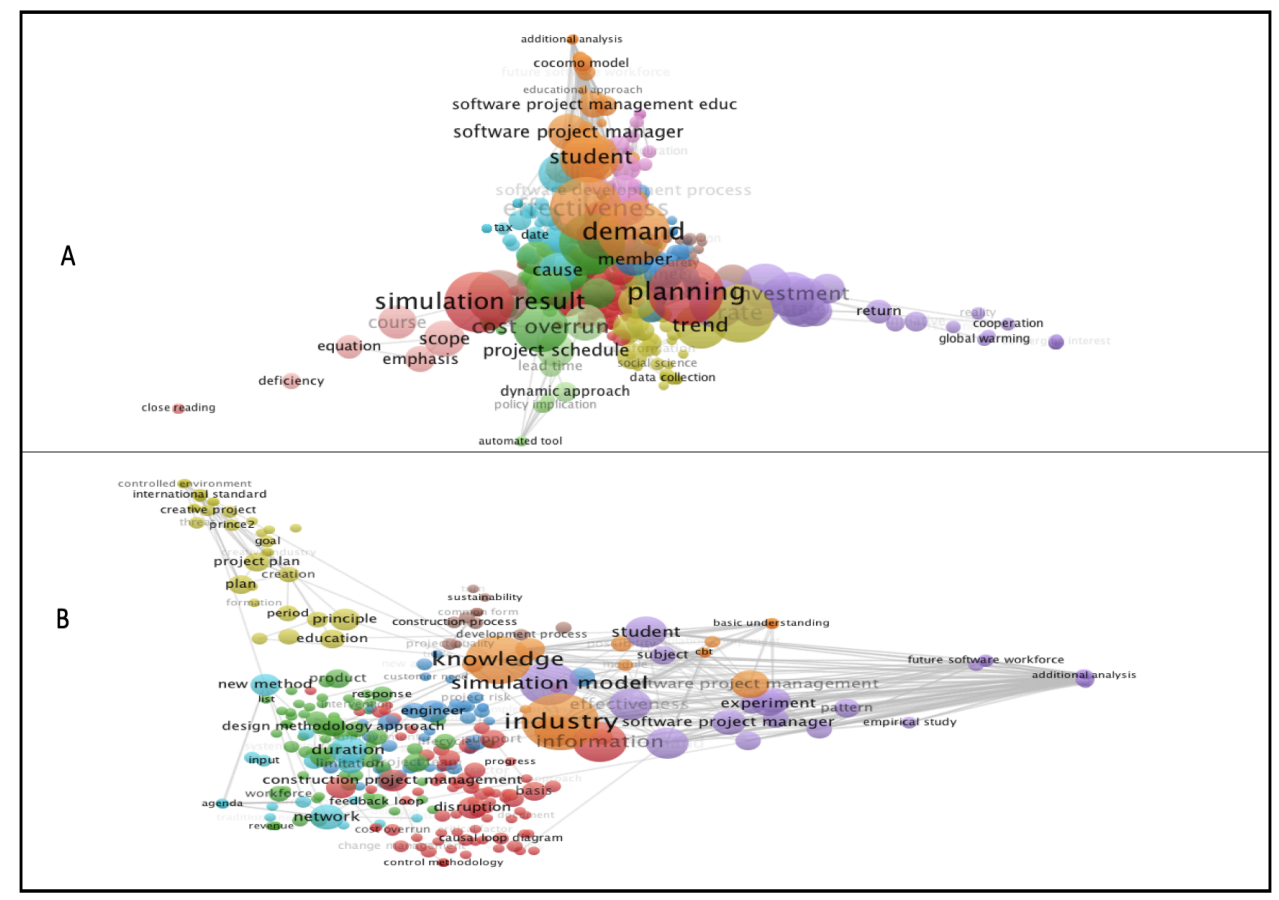

Figure 9 . Net formed by words used by Theme 1 papers.

From 90 words, considering the two bases, once more, there is not a single citation to the words "Programs" or "Programme", which seems to confirm that Theme 1 follows its trajectory, without any connection to the issues belonging to Theme 2 . Once Theme 1 has known results, all that is left is to verify if these results are being used in Theme 2 as a 
starting point for the development of its models. This will be verified in the qualitative step of this research.

\subsection{Qualitative analysis}

Papers from Theme 2 are summarized below in Chart 5. From the seven analyzed papers, two seek to develop dynamic models to leverage program management in the organizations, and five apply SD tools for problem resolution in areas that are related to program management.

Chart 5. Qualitative analysis of Theme 2 papers.

\begin{tabular}{|c|c|c|c|}
\hline Paper & Objective & $\begin{array}{l}\text { Program } \\
\text { Management } \\
\text { Problems }\end{array}$ & Research focus \\
\hline Els et al. (2006) & $\begin{array}{l}\text { To develop an approach, using } \\
\text { SD, to evaluate the impact of } \\
\text { project isolated risks as well as } \\
\text { combined risks, on the } \\
\text { program environment. }\end{array}$ & $\begin{array}{l}\text { Problems in } \\
\text { integrating risks into } \\
\text { the project-program } \\
\text { relationship causing } \\
\text { systemic effects. }\end{array}$ & \multirow{5}{*}{$\begin{array}{l}\text { Apply SD tools for } \\
\text { problem resolution }\end{array}$} \\
\hline Ruzzo (2015) & $\begin{array}{l}\text { To describe the creation of } \\
\text { artifacts, using systemic } \\
\text { impacts, in order to improve } \\
\text { decision-making in programs } \\
\text { of the Department of Defense } \\
\text { (DoD) of USA. }\end{array}$ & $\begin{array}{c}\text { Problems of } \\
\text { coordination between } \\
\text { projects. }\end{array}$ & \\
\hline Ngai \& Fenner (2016) & $\begin{array}{c}\text { To demonstrate how an NGO } \\
\text { can choose effective strategies } \\
\text { taking into consideration the } \\
\text { complex systemic interactions } \\
\text { in a program. }\end{array}$ & - & \\
\hline Samrah et al. (2017) & $\begin{array}{c}\text { To illustrate the variables that } \\
\text { are mentioned in the literature } \\
\text { to deal with unexpected risks } \\
\text { that threaten the success of } \\
\text { large programs. }\end{array}$ & $\begin{array}{c}\text { Problems of } \\
\text { coordination between } \\
\text { projects. }\end{array}$ & \\
\hline $\begin{array}{c}\text { Sales \& Barbalho } \\
(2018)\end{array}$ & \begin{tabular}{|} 
To identify and describe the \\
system archetypes that can \\
occur in program \\
management, improving the \\
decision- making process, and \\
consequently, increasing the \\
probability of organizations to \\
reach their strategic objectives \\
through successful programs.
\end{tabular} & \begin{tabular}{|} 
Short-term focus, \\
problem of \\
coordination between \\
projects, sharing of \\
resources and \\
problems with the \\
transformation of \\
organizations.
\end{tabular} & \\
\hline Becerril et al. (2016) & $\begin{array}{c}\text { To identify points of leverage } \\
\text { that influence the behavior of } \\
\text { programs, more specifically } \\
\text { those related to the integration } \\
\text { between program } \\
\text { management and systems } \\
\text { engineering. }\end{array}$ & \begin{tabular}{|} 
Problems in \\
integration between \\
projects and lack of \\
integration of \\
programs with \\
systems engineering.
\end{tabular} & \multirow[t]{2}{*}{ Dynamic models } \\
\hline Sales et al. (2017) & $\begin{array}{c}\text { To identify and to describe } \\
\text { how SD, through system } \\
\text { archetypes, can be used to } \\
\text { demonstrate the importance of } \\
\text { benefit management in } \\
\text { programs. }\end{array}$ & $\begin{array}{c}\text { Short-term focus, } \\
\text { problem of } \\
\text { coordination between } \\
\text { projects and resource } \\
\text { sharing. }\end{array}$ & \\
\hline
\end{tabular}


From the analysis of Theme 2 (Dynamic models), one realizes that there is an initial attempt to develop models for Progrma Management (DPgM). Becerril et al. (2016) use a dynamic model to represent DPgM, however, with a structure based on DPM research, without taking into consideration variables appropriate to program management, such as benefits management. According to Sterman (2000), the main principle of SD states that the structure of the system gives birth to its behavior. To Walenta (2016), programs and projects are so different that it is necessary to promote the idea, within the organizations, that the separation between projects and programs is critical to the success of both. In other words, projects and programs have behaviors that are very different, not allowing them to be studied through the same structure. Despite this, this research shows that the question of integration and exchange of information among projects is important to programs, mainly to the ones presenting strong pressure over its schedule.

Sales et al. (2017), proposed a model for DPgM with characteristics and controls of program, including development process and mental models for decision-making, as well as the components of a program, however, there is no detailing about rework cycle as well as domino effects, although the research approaching system archetypes. This way, despite representing advances towards a DPgM model, dealing specifically with the structure of a program, this model still needs to evolve, as it presents only two out of four fundamental structures of DPM observed by Lyneis \& Ford (2007), that included four components: the characteristics of the projects, which include the processes for development, the mental models for decision making and components from projects; rework cycle, the most important feature of project dynamics models, because it includes in the dynamic models the recursive nature in which rework generates more rework; project controls, for comprehension of the variable system's performance; and the ripple and knock-on effects, in other words, the unintentional consequences of the decisionmaking process.

From the analysis of Theme 2 (Apply SD tools for problem resolution), two of them approach the issue of risk management in programs, one approaches the question of procurement and changes, one discusses decision-making for a technical solution used in a program, and the last one identified four system archetypes from problems in program management approaches.

Els et al. (2006) and Samrah et al. (2017) deal with risk management in programs. Samrah et al. (2017), state that there are differences between concepts of projects and programs, judging as an error to consider them the same entity, or even to use the same structures to manage them, as each one of these areas has lifecycles with their characteristics and different objectives to be reached. This research developed an initial qualitative model with variables identified in the literature of risks already mapped, which can generate positive or negative influences in programs. Els et al. (2006) show how risks in the program environment can spread themselves fast and generate unpredictable domino effects. Despite this, these researchers use the DPM model, to evaluate the effects of the propagation of such risks in the program environment. In other words, the proposal of modeling does not use variables related to programs, for example, to analyze the impact of risks to benefits.

Ruzzo (2015), states that there are consistent differences between the environments of projects and the environments of programs, in particular with regards to complexity and risks associated to the system formed in a program, that possesses various projects. The research uses SD with other tools, such as Design Structure Matrix (DSM), to map interdependencies among the various components that form the "program" system. With the intent to bring forward eventual impacts from non-planned changes in defense programs, that can generate integration problems, in particular in the integration of the 
procured solutions, it was proposed an integrating framework with seven steps. What calls attention in this framework is the concern in integrating traditional tools of project and program management to SD, in program management decisions, which can already be considered as an advance in regards to the research of Theme 2 .

The research by Ngai \& Fenner (2016) builds a model with the four fundamental structures of dynamic models observed by Lyneis \& Ford (2007), however, these structures were not developed with the intents of developing a model to DPgM, but to the analysis of possible strategies to be used in the decision making related to a technical solution that influenced the results from the studied endeavor by said research.

Lastly, the research by Sales \& Barbalho (2018), identified and described four system archetypes that can occur in a program management environment, that undermine key components of program management, like the benefits management, the governance structure, the stakeholder management, and the financing. The authors showed that the problem of short-term vision impacts the achievement of outcomes and benefits by programs, and the new capabilities delivery by the projects is not enough to hold an effective stakeholder's engagement.

Excepting the research by Ngai \& Fenner (2016), focused on specific problems from the water supply program, to the other researches show the main problems in the program management traditional approaches: short-term focus, the problem of coordination between projects and resource sharing.

\subsection{Discussion}

Based on the results of this systematic review, it is possible to assume a series of implications for the development of researches that relate system dynamics to the management of environments of concurrency of projects and programs.

According to quantitative analysis, DPM is a theme with relevant researches, with papers cited in important journals, which contributions have shown models focused to resolve the problems from traditional project management approaches. However, Dynamic Program Management (DPgM) researches have a long way to develop.

About a possible confusion regarding the projects and programs concepts, it seems not to occur in the DPM literature, because, after the analysis of the keywords, title and abstract, the words "program" and "programme" were not detected/used, which makes it seem that research about DPM is project-focused. However, it was noted the use of the term "governance" as a keyword in recent DPM researches. This concept is important to program management because programs are effective means to create a governance structure that provides a bridge between projects and the organizational strategy (Shao \& Muller, 2011) and as a structure that influences the projects coordination and the resources management (Sales et al., 2017). In other words, it seems to be possible to explore this convergence on the DPgM researches.

Besides this, still regarding the researches about DPgM, it was verified that many papers use the project dynamic structure to simulate the behavior of a program, in other words, do not use program-specific variables, such as "benefits" or "capabilities", core variables of this field. So, an aspect that needs to be defined in DPgM, as it is the basis to the definition of its models itself, is the question regarding the behavior of a program. As such, the analyzed DPM models structure a project as a continuous flow of work packages, with numerous variables, not always intuitive, that influence the results of a project. What will flow through the stocks of the DPgM models? 
In the analyzed papers of Theme 2, for example in Becerril et al. (2016) and Sales et al. (2017), what continues to flow are the work packages. However, these work packages are typical of projects that are components of programs. When such work packages are integrated into new capabilities, results, and benefits, will they continue to behave as a flow of work packages? It doesn't seem reasonable.

Further, only one paper appropriately addresses the use of SD in program management, with the structure of the model using the variables "Benefits" and "Governance": "Improper Program Management Induced System Archetypes" (Sales et al., 2017). However, this research does not use in its model the control mechanisms, and the behavior of the rework cycle is not adequately presented, thus only being able to be seen as initial research that needs further improvements. According to Sterman (2000), the development of a dynamic model must have a clear purpose, taking into account the problems that afflict the system. Luna-Reyes \& Andersen (2003), showed that the main authors of the SD area, begin the development of dynamic models defining the problems that need to be modeled and trying to understand the relation of these problems with the systemic perspective. Unfortunately, none of the analyzed models seems to have considered this recommendation.

Additionally, what are the problems in the program management approaches? Sales \& Barbalho (2018) try to discuss this topic through the use of system archetypes. This research identified and described four system archetypes that can occur in program management and mapped, from these archetypes the main problems in program management approaches short-term focus, the problem of coordination between projects, sharing of resources, and problems with the transformation of organizations. These problems are aligned with the other papers analyzed, which can be an important basis for DPgM development.

As presented in this study, the dynamic models used in projects have four fundamental structures. The rework cycle, for example, explains many of the issues of traditional approaches, such as the "syndrome of 90\%". Sales \& Barbalho (2018) showed ripple and knock-on effects through the system archetypes and a rework cycle. The rework cycle was presented through the need to transform the organizations (the delivery of organizational capabilities based on their context) so that the technical capabilities could generate results and benefits. For Shao \& Muller (2011), the context of a program is associated with the need for matching the program to the organization as a whole and should take into account the organizational adequacy, organizational stability, and the resources involved.

As such, delays in the delivery of organizational capabilities can generate rework cycles, as these organizations cannot deal only with the absorption of technical capabilities, thus turning the realization of benefits into an impossible endeavor. Over time, these delivered capabilities that were not converted into benefits become obsolete. For these capabilities to become useful again, they must return to the project environment, generating additional costs that are not always viable, thus possibly becoming white elephants. Rebentisch (2017) explains that white elephants (something that costs a lot of resources and attention to be developed but that does not have utility when ready) are created by programs when the capabilities cannot be converted into benefits due to issues associated to planning activities held at the program level.

The understanding of the domino effect within dynamic modeling minimizes the occurrence of system archetypes. The use of control actions allows managers to take action regarding certain variables to understand the results expected from a predetermined initial configuration. In this sense, it seems DPgM models need to incorporate these structures, so they can become effective to companies that manage programs, also 
is needed for the analysis of if new structures would also be adequate to meet the characteristics that are unique to a program.

In other words, the researchers from Theme 2 are still found to be in an early stage, thus needing to evolve in the following ways: identification of the problems from traditional approaches to program management that hinder the benefits delivery to organizations (it is possible to use the problems already pointed out in this research); the definition of the fundamental structures for DPgM (knock-on effects and a rework cycle were both pointed out in this research); and the definition of the specific workflow for the management of programs, with the specific variables from this domain (capabilities and benefits seem to be important variables for this purpose).

The results presented in this paper show that despite the growing use of program management by the organizations (Shehu \& Akintoye, 2010) and of the apparent necessity of the use of systemic thinking within the scope of program decision making, little research was developed to integrate these two fields. Besides this, still regarding this little research, not always the variables, the structures, and the specific problems of program management are taken into consideration by them.

Lyneis \& Ford (2007), in a literature review that has become a reference for research in the field of project management and system dynamics, question the research on the application of systems dynamics that has only advanced to improve the understanding of individual projects. These authors suggest the need for the advance of research on the development of SD models for leveraging the management of multiple projects, as it is the case of programs. What was observed is that after more than ten years of this literature review was done, there has been no significant progress towards the use of SD in the area of program management.

However, important questions for program managers were presented on this paper, with problems originating from the short term vision (due to the current mentality being tightly linked to project management), the difficulty with regards to the coordination among projects (due to competition among these efforts) and the traps found on the resource sharing. These problems must be analyzed also through the perspective of systemic thinking (as it has been done successfully already regarding project management) so that the organizations become more effective when delivering benefits through the management of their programs.

Besides this, an important discovery was the identification of a rework cycle, very common to program management, which can be modeled through SD tools: technical capabilities that are not able to generate the results/benefits due to inefficiencies on the organizational capabilities, leading to the creation of the so-called "white elephants". Besides this, variables and specific problems of program management were as the base for the development of a future dynamic model, which so far does not exist for program management.

Also, Lyneis \& Ford (2007) and Randers (2019) pointed out that even with the great success of research in the area of project management and SD, there are few practical applications of this tool in projects, which in turn requires the publication of more success stories on the integration between SD and project management. More research with pure predictive models can also improve the utilization of SD theory in project management (Barbalho et al., 2019a). The literature on programs and SD seems to suffer from the same problem: it focuses only on proposing theoretical models, while at the same time it brings very scarce examples of implementation and practical results. Only Ngai \& Fenner (2016), despite not discussing program variables, seek to show a history of success in decision making based on the use of SD in a program, a good example of the kind of research SD theory allows in program management. 
It seems to be a good idea, that to speed up acceptance by organizations, research on the development of models for DPgM is to be validated by practical application stories and proven improvements in the enablement of decision making, ultimately leading these program efforts to their success.

\section{Conclusion}

The objective of this paper was to obtain a more accurate vision of how SD is being used in the development of program management fields, including the identification of new paths that are absent in the current literature. The use of SD in the field of project management showed itself to be quite relevant, with high-impact publications in a process of continuous improvement. This maturity and continuity were not observed in the field of program management, with researches being found in a very early stage.

Despite the success of the application of SD in the project management field, this success did not advance over correlate areas, thus this contributing very shallowly to the field of program management. In the case of SD in the program management field, there is an aggravating factor, since the theoretical bases of this area are still not well understood, which makes the project dynamic models to be used in a program environment, not taking into account this area's specific variables.

Dynamic models are being used to improve the performance of programs, however, few studies take into consideration their fields' specific variables, thus the researches can only be viewed as very fragmented.

An important contribution of this research was to reveal an agenda (or guidelines) for the development of SD in the program management field. Suggestions for future researches, besides the proposed agenda, need to take into consideration the need for continuity in the development of dynamic models for projects, to analyze the projects that are developed in a program environment. It would also represent an important contribution to the industry and to the academia the realization of researches to leverage the initial models that are under development in the field of management of dynamic programs, which can help to solve multiple real problems of programs that are poorly understood, because of lack of theoretical background.

As limitations of this research, we can cite the fact that each one of the themes could have been explored uniquely and separately when researched, which would have increased the sharpness of the analysis. Besides this, the group of studied papers was limited to the ones published during the XXI century. The use of early researches, particularly the ones in the field of dynamic projects could bring forward other authors that also contributed to the development of the research field.

\section{References}

Artto, K., Martinsuo, M., Gemünden, H. G., \& Murtoaro, J. (2009). Foundations of program management: a bibliometric view. International Journal of Project Management, 27(1), 1-18. http://dx.doi.org/10.1016/j.ijproman.2007.10.007.

Barbalho, S. C. M., Carvalho, M. M., Tataves, P. M., Quintero, C. H. L., \& Leite, G. A. (2019a). Exploring the relation among product complexity, team seniority, and project performance as a path for planning new product development projects: a predictive model applying the system dynamics theory. IEEE Transactions on Engineering Management, 66, 1-14. http://dx.doi.org/10.1109/TEM.2019.2936502. 
Barbalho, S. C. M., Leite, G. A., \& Carvalho, M. M. (2019b). Using System Dynamics for Simulating Mechatronic New Product Development. In: J. Reis, S. Pinelas, \& N. Melão (Eds.), Springer Proceedings in Mathematics and Statistics (pp. 195-206). Cham: Springer. http://dx.doi.org/10.1007/978-3-030-14969-7_17.

Becerril, L., Rebentisch, E., Chucholowski, N., \& Conforto, E. (2016). A simulation-based analysis on the integration of program management and systems engineering. In: International Design Conference, (pp. 1835-1844). Dubrovnik: IDCA.

Booth, A., Papaioannou, D., \& Sutton, A. (2013). Systematic approaches to a successful literature review. London: England: Sage Publications Ltd.

Conforto, E., Rossi, M., Rebentisch, E., Oehmen, J., \& Pacenza, M. (2013). Survey report: Improving integration of program management and systems engineering. In: 23rd INCOSE Annual International Symposium. Philadelphia: INCOSE.

Cosenz, F. (2017). Supporting start-up business model design through system dynamics modelling. Management Decision, 55(1), 57-80. http://dx.doi.org/10.1108/MD-06-2016-0395.

Danwitz, S. (2017). Managing inter-firm projects: a systematic review and directions for future research. International Journal of Project Management, 36(3), 525-541.

Els, S. A., Reichelt, K. S., \& Cooper, K. G. (2006). Quantifying the impact of multiple risks on software-intensive programs. the journal of defense modeling and simulation: applications, methodology. Technology, 3(4), 207-216.

Ford, D., \& Sterman, J. (2003). Overcoming the $90 \%$ syndrome: iteration Management in concurrent development projects. Concurrent Engineering, Research and Applications, 11(3), 177-186. http://dx.doi.org/10.1177/106329303038031.

Luna-Reyes, L., \& Andersen, D. (2003). Collecting and analyzing qualitative data for system dynamics: methods and models. System Dynamics Review, 19(4), 271-296. http://dx.doi.org/10.1002/sdr.280.

Lyneis, J. M., \& Ford, D. N. (2007). System dynamics applied to Project Management: a survey, assessment, and directions for future research. System Dynamics Review, 23(2-3), 157-189. http://dx.doi.org/10.1002/sdr.377.

Martinsuo, M., \& Hoverfält, P. (2018). Change program management: toward a capability for managing value-oriented, integrated multi-project change in its context. International Journal of Project Management, 36(1), 134-146. http://dx.doi.org/10.1016/j.ijproman.2017.04.018.

Martinsuo, M., \& Lehtonen, P. (2007). Program and its initiation in pratice: development program initiation in a public consortium. International Journal of Project Management, 25(4), 337-345. http://dx.doi.org/10.1016/j.jpproman.2007.01.011.

Ngai, T., \& Fenner, R. A. (2016). Designig programme implementation strategies to increase the adoption and use of biosand water filters in rural India. Water Alternatives, 7(2), 320-341.

Oraee, M., Hosseini, R., Papadonikolaki, E., Palliyaguru, R., \& Arashpour, M. (2017). Collaboration in BIM-based construction networks: a bibliometric-qualitative literature review. International Journal of Project Management, 35(7), 1288-1301. http://dx.doi.org/10.1016/j.jpproman.2017.07.001.

Randers, J. (2019). The great challenge for system dynamics on the path forward: implementation and real impact. System Dynamics Review, 35(1), 19-24. http://dx.doi.org/10.1002/sdr.1623.

Rebentisch, E. (2017). Integrating Program Management and System Engineering. New Jersey: Jonh Wiley \& Sons.

Reis, A., Barbalho, S., \& Zanette, A. (2017). A bibliometric and classification study of Project-based Learning in Engineering Education. Production, 27(spe), 1-16. http://dx.doi.org/10.1590/01036513.225816 .

Rezende, L. B., Blackwell, P., \& Gonçalvez, M. D. (2018). Researches focuses, trends, and major findings on project complexity: a bibliometric network analysis of 50 years of project 
complexity research. Project Management Journal, 49(1), 42-56.

http://dx.doi.org/10.1177/875697281804900104.

Ruzzo, A. (2015). DoD predictive program management. In: Proceedings of the 17th International DSM Conference Fort Worth (pp. 97-107). Texas: Carl Hanser Verlag GmbH and Co. KG.

Sales, L., \& Barbalho, S. (2018). Indentifying system archetyes in order to comprehend and improve the Program Managemet practices in organizations. IEEE Transactions on Engineering Management, 67(1), 1-11.

Sales, L., Augusto, R., \& Barbalho, S. (2017). Improper Program Management induced System Archetypes. Procedia Computer Science, 114, 73-82. http://dx.doi.org/10.1016/j.procs.2017.09.012.

Samrah, R., Shaalan, K., \& Ali, A. (2017). System dynamics modeling for the complexity of knowledge creation within adaptive large programs management. Recent Advances in Intelligent Systems and Computing, 569, 3-17. http://dx.doi.org/10.1007/978-3-319-56535-4_1.

Shao, J., \& Muller, R. (2011). The development of constructs of program context and program success: a qualitative study. International Journal of Project Management, 29(8), 947-959. http://dx.doi.org/10.1016/j.ijproman.2011.02.003.

Shehu, Z., \& Akintoye, A. (2010). Major challenges to the successful implementation and practice of programme management in the construction environment: a critical analysis. International Journal of Project Management, 28(1), 26-39. http://dx.doi.org/10.1016/j.jproman.2009.02.004.

Sterman, J. D. (2000). Business dynamic: system thinking and modeling a complex world. Boston: McGraw-Hill.

Trammell, T., Moulton, A., \& Madnick, S. (2016). Effects of funding fluctuations on software development: a system dynamics analysis. Engineering Management Journal, 28(2), 71-85. http://dx.doi.org/10.1080/10429247.2016.1155390.

Van Eck, N. J., \& Waltman, L. (2010). Software survey: VOSviewer, a computer program for bibliometric mapping. Scientometrics, 84(2), 523-538. http://dx.doi.org/10.1007/s11192-0090146-3. PMid:20585380.

Walenta, T. (2016). Projects and programs are two different animals, don't underestimate the gap. Procedia: Social and Behavioral Sciences, 226, 365-371. http://dx.doi.org/10.1016/j.sbspro.2016.06.200.

Williams, T. (2005). Assessing and moving on from the dominant project management discourse in the light of project overruns. IEEE Transactions on Engineering Management, 52(4), 497-508. http://dx.doi.org/10.1109/TEM.2005.856572.

Yuan, H., Chini, A., Lu, Y., and Shen, L. (2012). A dynamic model for assessing the effects of management strategies on the reduction of construction and demolition waste. Waste Management, 32(3), 521-531. http://dx.doi.org/10.1016/j.wasman.2011.11.006.

Zhang, X., Yuzhe, W., Liyin, S., \& Martin, S. (2014). A prototype system dynamic model for assessing the sustainability of construction projects. International Journal of Project Management, 32(1), 66-76. http://dx.doi.org/10.1016/j.jproman.2013.01.009. 